\title{
The Relevance of THE HiP EXTENSOR MusCles TO LOW BACK PAIN IN Elite Female Field Hockey Players
}

\begin{abstract}
Low back pain (LBP) is a common complaint among field hockey players. Only a few of the risk factors for LBP have however been assessed on these players. These include trunk strength and lumbosacral range of motion. The aim of the literature review was therefore to investigate the reports of LBP among elite female field hockey players, focusing on risk factors for LBP, biomechanical aspects of field hockey, muscle imbalance and the role of the gluteus maximus (GM) muscle in the development of LBP. The literature indicated a strong link between LBP and GM weakness. More recent research supports this concept and clearly stated that female athletes with GM weakness are at risk for the develop-

Wege M, MScPhysio (US) ${ }^{1}$; Bester MM, MScPhysio (UWK); Crous LC, MScPhysio (US) ${ }^{3}$

${ }^{1}$ Private Practitioner, Accredited Lecturer Physiotherapy Department,

Stellenbosch University.

2 Head: School of Allied Health Sciences, Stellenbosch University.

Senior Lecturer Physiotherapy Department, Stellenbosch University. ment of LBP. Considering that the biomechanical aspects and unique requirements of field hockey indicate hip extensor involvement, as well as the association between LBP and GM weakness, further investigation is warranted into the hip extensor muscles of field hockey players.
\end{abstract}

\section{KEY WORDS: LOW BACK PAIN; HIP EXTENSORS; FEMALE FIELD HOCKEY; MUSCLE IMBALANCE.}

\section{This Literature Review was conducted in partial fulfillment of the requirements for a Master's degree at Stellenbosch University, South Africa.}

\section{INTRODUCTION}

A review of the literature on field hockey indicated that despite the popularity of the sport, only a few studies have been conducted to attain more information about the injury patterns and risk factors for injuries. Regarding low back pain (LBP) Murtaugh (2001) established that $59 \%$ of field hockey players studied experienced back pain, mainly of the lower back. Furthermore there is a strong indication in the literature that weakness of the hip extensor muscles plays an important role in the development of LBP (Janda 1986; Kankaanpää et al. 1998; Leinonen et al. 2000; Nadler et al. 2000, 2001). Recent research suggests the screening of hip extensor strength in the prevention of LBP in female athletes (Nadler et al. 2000, 2001).

The aim of this literature review was therefore to investigate the reports of LBP among elite female field hockey players. This overview of the literature considers LBP among field hockey players, focusing on risk factors for LBP, biomechanical aspects of field hockey, muscle imbalance and the role of the gluteus maximus (GM) muscle in the development of LBP. The article is concluded by a discussion of the clinical relevance and implications of the findings of the review.

\section{LBP AMONG FIELD HOCKEY PLAYERS}

The study by Murtaugh (2001) highlighted the occurrence of LBP and is supported by previous studies documenting 53\% (Reilly \& Seaton 1990) and $78 \%$ (Lindgren \& Twomey 1988) of hockey players suffering from LBP. Other studies however report a lower incidence of LBP: 5\% (Petrick et al. 1992), 9.4\% (Watson 1997) and 8.9\% (Fuller 1990) of the total injuries. This apparent controversy in the literature could be due to the following differences in methodology:

1) Different methods of data collection (survey versus direct reporting). In most of the studies with higher prevelance, injuries were self reported and relied on the athlete's ability to accurately recall his/her injuries (Lindgren \& Twomey 1988; Murtaugh 2001). Fuller (1990), Petrick et al. (1992) and Watson (1997) improved on this by doing prospective studies on injury patterns.
2) Inconsistent variables, i.e. the level of experience, the surface hockey is played on, age, sex, etc. Stevenson et al. (2000) states that it is to be expected that injuries will differ among professional, elite and social players.

3) Varied definitions of injuries and classification of the degree of injury (severe, moderate, minor).

Results of studies should be seen in the context within which the particular study was conducted and therefore caution must be taken to generalise the data regarding LBP across studies.

\section{RISK FACTORS FOR LBP}

When considering LBP among field hockey players, it is important to take into account risk factors of LBP, as well

\section{CORRESPONDENCE TO:}

Marina Wege

PO Box 785, Durbanville 7551

South Africa

Tel: $\quad$ +27219389300 (Work) +27 219750026 (Home)

Fax: $\quad+27219761292$ or

Email: mmb1@sun.ac.za lcc@sun.ac.za 
as recent changes in the game. The speed of field hockey has increased due to several factors, securing constant involvement of all players on the field, thus minimising their recovery period. Since 1996 field hockey has undergone certain rule changes, including the change of the offside rule and regular substitution of players. Elite players now practise and play on synthetic surfaces, necessitating the player to maintain a much lower body position in order to achieve better skill during stopping, flicking and tackling. These changes might be seen as a risk factor to the development of LBP due to the effect on the musculoskeletal system. In view of the relevant changes of the game and their influence on the posture of the hockey player, it is questionable whether previous studies still represent what is currently applicable to the game. Taking this into account, the source of information concerning injuries in the sport is limited and highlights the need for current data on field hockey.

Several risk factors for LBP have been reported in the literature: decreased flexibility of the hip flexors, hamstrings and/or rectus femoris (Biering-Sorenson 1984; Fairbank et al. 1984); leg length discrepancy (Giles \& Taylor 1981); sacroiliac joint dysfunction (Indahl et al. 1999; Schwarzer et al. 1995); reduced trunk strength (McNeill et al. 1980); acquired ligament laxity and/or overuse injury of the lower extremity (Nadler et al. 2000) and reduced lumbosacral range of motion (ROM) (Mayer et al. 1984).

Only a few of these risk factors for LBP have been assessed on field hockey players. Reilly \& Seaton (1990) highlighted the unique stress of field hockey on the spine. They established that seven minutes of dribbling a hockey ball could cause an average spinal shrinkage of $2.73 \mathrm{~mm}$ and that dribbling can increase energy expenditure from normal running by $15-16 \mathrm{~kJ} \mathrm{~min}^{-1}$. They concluded that the physiological strain and spinal loading distinctive to field hockey are most likely due to the peculiar postural requirements of the game.

Fenety \& Kumar (1992) investigated trunk muscle strength and spinal mobility as risk factors for LBP in elite female field hockey players. Their results indi- cated that hockey players with LBP had:

- weaker peak and average eccentric extension trunk strength compared to the control group;

- significant loss of lumbosacral extension and total lumbosacral ROM compared to pain-free hockey players and the control group; and

- no significant difference in lordosis from the control group.

It was concluded that female hockey players, regardless of the occurrence of LBP, are at risk of reduced lumbosacral ROM and trunk extension strength. These results are however not entirely supported by earlier research. Lindgren \& Twomey (1988) found elite hockey players to have:

- strong trunk extensors and flexors;

- no obvious relationship between lumbar ROM and LBP and

- a long, flat thoracolumbar spine, with some muscle asymmetry on the right.

The controversy in the above two studies could be due to differences in measurements of outcome. Fenety \& Kumar (1992) used photographs for ROM measurement on female players, while isokinetic testing of the trunk muscles was conducted throughout the functional range required to play field hockey. This was an improvement on the single position isometric test, as well as lumbar spondylometer and rotameter used by Lindgren \& Twomey (1988) on male and female players. Gender specific differences are noted elsewhere in the literature (Nadler et al. 2000), indicating a significant side-to-side hip extension strength difference among females but not males. This could contribute to differences in results.

The hip extensor muscles are another possible contributing factor to LBP in field hockey players. Fenety \& Kumar (1992) suggested hip extensor strength testing as part of the functional assessment of field hockey players. Considering the hip musculature, Porterfield \& DeRosa (1998) stated that the muscles from below (muscles of the hip and knee joint) and the muscles above the pelvis (muscles of the lumbar spine and abdominal wall) are responsible for proper reduction of forces through the lumbar spine. The powerful hip muscles cross the sacroiliac joint and are mechanically linked to the muscles of the lumbar spine, thus they are able to influence the lumbopelvic area (Porterfield \& DeRosa 1998). The thoracolumbar fascia functions as this mechanical link and according to Vleeming et al. (1995) plays an integrated role in trunk rotation and load transfer within the kinetic chain. The fascia is tensed by contraction of various muscles, including the latissimus dorsi, GM and erector spinae (ES), contributing to stability of the lumbar spine and pelvis (Vleeming et al 1995). With decreased muscle strength of any of these muscles, the efficiency of the posterior layer will be affected, decreasing force closure and therefore stability of the lumbar spine and sacroiliac joint (Vleeming et al 1995). Vogt et al (2003) suggested that changes in the recruitment pattern of the hip extensor muscles are a factor in the development of LBP. Nadler et al. (2000) confirmed this by stating that poor hip muscle control may increase an individual's risk for the development of LBP. The authors argued that the transfer of forces from the lower extremity to the spine is jeopardised. All these factors reinforce the association between the hip muscles and the lumbar spine. It must however not be seen in isolation from the biomechanical requirements of field hockey.

\section{BIOMECHANICAL ASPECTS OF FIELD HOCKEY}

A review of the biomechanical aspects of the game, including the sustained posture and repeated movements, indicates the possibility of hip extensor muscle imbalance.

\section{Posture}

Field hockey is a game with an inbuilt asymmetry. Sticks are designed for right-handed use and the rules require that only one side of the stick may be used. Ball-handling skills such as dribbling, hitting, flicking and pushing are executed in a position of spinal and hip flexion, requiring considerable muscle strength and endurance. Fox (1981) described this position as an ergonomically unsound posture for fast controlled locomotion due to the spinal flexion demand of the game. This semi-crouched position must be sustained for the best 
part of the game, lasting 70 minutes, and for the greater part of a two-hour training session for elite players (Lindgren \& Twomey 1988).

Karlsson \& Jonsson (1965) and Marzke et al. (1988) confirmed GM recruitment as a hip extensor during a crouched (squatting) position, controlling flexion and rotation of the trunk on the femur. Marzke et al. (1988) further highlights GM involvement in activities where the trunk is used for leverage to increase the force and velocity to hand-held tools. These aspects describe biomechanical components of field hockey. In addition, the ball is hit and pushed with force during play. Therefore the unique postural requirements of the game necessitate considering the lumbar spine and surrounding muscles, and the muscles around the hip, especially the hip extensor muscles.

\section{Repeated movements and sustained postures}

Sahrmann (2002) states that repeated movements and sustained postures can change a muscle(s) strength and length, eventually changing the movement pattern, thus causing impairment. This confirms the risk of the hip extensor muscles in field hockey players. It has to be realised that even athletes are at risk for undesirable changes in movement components, resulting in the development of movement impairments, tissue stress, microtrauma and eventually macrotrauma (Sahrmann 2002). Taking into account the role that the GM plays during hockey, it could easily be assumed that it would be adequate to strengthen the muscle. However, considering the work by Janda (1978) and Sahrmann (2002), this muscle is prone to weakness and the repeated movements could lead to adaptation of the GM muscle length and strength, thus affecting the movement pattern (delayed timing or recruitment deficiency). These changes could eventually contribute to a muscle imbalance, especially around the hip. It is also uncertain whether or not the asymmetry of the sport results in asymmetry of lower extremity muscle strength.

\section{MUSCLE IMBALANCE}

As far back as 1978, Janda defined muscle imbalance as an impaired relation- ship between muscles that are prone to develop tightness and shortness and muscles that are prone to inhibition and weakness. Muscle imbalance can manifest as differences between side-to-side (right versus left), the agonist-antagonist (Grace 1985) or synergists (Sahrmann 2002). The suggestion has been made that this muscle imbalance must not be viewed in isolation from movement patterns (Richardson et al. 1999; Sahrmann 2002; Schlink 1990). From the literature it is evident that the movement patterns are investigated by assessing the:

- muscle recruitment/firing order, thus the timing/onset of activation (Hodges \& Richardson 1996; Pierce \& Lee 1990; Richardson et al. 1999, 2000); and/or

- muscle activity, thus the level of contribution described as a percentage of maximum voluntary isometric contraction (MVIC) (Richardson et al. 2000; Souza et al. 2001).

Pierce \& Lee (1990) suggested that there might be a link between these two aspects, for changes in muscle recruitment order may be due to changes in EMG muscle activity.

According to Janda (1978) and Sahrmann (2002) the GM is prone to weakness and the hamstring prone to tightness. Weakness of the GM results in increased activity of the thoracolumbar ES and hamstring during hip extension, thus abnormal muscle activity (Schlink 1990; Vogt \& Banzer 1997). With regards to muscle firing order, GM recruitment is often delayed; taking place at the end of hip extension, after an abnormal lumbopelvic position or an anteverted pelvis and hyperlordotic lumbar spine has been achieved (Schlink 1990). This poor hip muscle control may jeopardise the transfer of forces from the lower extremity to the spine (Nadler et al. 2000). This may explain why Singer (1986) advocated that lumbar assessment include the evaluation of muscle firing order of the hip extensor muscles during active prone hip extension (APHE). Contradicting this proposal, a study by Pierce \& Lee (1990) indicated that there is no 'consistent' firing order of the hip extensors among healthy subjects without any LBP history. However, a more recent study investigating APHE from neutral showed a more consistent muscle firing order of ipsilateral ES, semitendinosus, contralateral lumbar ES, tensor fascia latae and GM (Vogt \& Banzer 1997). This discrepancy could be due to the difference in chosen ROM. According to Vogt \& Banzer (1997) APHE from $30^{\circ}$ (hip flexion to neutral) (Pierce \& Lee 1990) excludes any accompanying movement of the trunk and may therefore not be directly comparable to APHE that starts at neutral.

The question now arises whether the muscle firing order and/or muscle activity of healthy subjects participating at a high level of the same activity would be any different from the previous studies? Mayer (1987) suggests that athletes training in a physically demanding sport deserve being compared to a sportspecific database. Sport played at a high level contributes to adaptation specific to that sport, which will not necessarily be the case in sedentary individuals. Differences in strength of synergists could be contributed to a specific sport (Sahrmann 2002). The posture hockey is played in, and the fact that the muscles around the hip are functioning in a closed kinematic chain, contributing to the distribution of forces up the spine, warrants further assessment. The strength and endurance of the hip extensor muscles can indirectly influence the lumbar spine (Nadler et al 2000).

\section{The kinetic chain}

According to the kinetic chain or link theory of Nicholas et al, as far back as 1977, muscle imbalance cannot be seen in isolation. The lower extremity kinetic chain functions as a unit, implicating that any change in the unit will have repercussions on the rest of the unit. Any lower extremity injury or dysfunction will therefore have implications on the rest of the kinetic chain. Several more recent studies support this finding (Beckman \& Buchanan 1995, BullockSaxton 1994). The theory is further reinforced by research supporting the proposed link between muscle imbalance, lower extremity injuries and/or LBP in athletes (including sport such as volleyball, soccer, swinning, track, tennis, basketball) (Knapik et al. 1991; Nadler et al. 1998, 2000, 2001). The kinetic 
chain theory therefore reinforces the association between the hip musculature and lumbar spine and confirms the relevance of the hip muscles in the development of LBP. Research specifically indicates an association between female athletes with significant asymmetric hip extensor muscle strength and the development of LBP (Nadler et al 2001).

Dysfunction in the kinetic chain is therefore a complex interaction of the articular, muscular and neural systems. When considering the link between the GM and LBP in the lumbo-pelvic hip complex, the effect of inappropriate recruitment of movement synergists around the hip should be considered. According to Sahrmann (2002) even athletes are at risk for muscle imbalance between synergists: one muscle being notably weaker than its synergist. EMG studies by Sahrmann (2002) indicate that extreme variation from the normal recruitment patterns and timing of synergists may contribute to imbalance within force couples. If one muscle is dominant and contributes more force to a particular movement (e.g. hamstring instead of GM in APHE), then the other muscle(s) are required to contribute less, leading to impairment of the less dominant muscle (e.g. GM). Delayed recruitment of the less dominant muscle can be reflected in decreased muscle strength. Therefore, the susceptibility of the dominant muscle for an overuse syndrome (e.g. hamstring) increases. Sahrmann's (2002) assessment of movement patterns therefore considers the muscle firing order (e.g. delayed GM recruitment) and muscle activity (e.g. GM contributing less force to the movement).

\section{Gluteus Maximus and Low Back Pain}

Janda's (1986) speculation about reduced GM activity in patients with LBP is supported by recent studies. Kankaanpää et al. (1998) and Leinonen et al. (2000) demonstrated poor endurance of the GM in patients with chronic LBP. Vogt et al. (2003) suggested that the role of the GM and hamstring muscles are often overlooked in the development of pain syndromes in the lumbar/sacral/hip region. Nadler et al's (2000, 2001) research adds validity to the association between hip muscle imbalance and LBP among female athletes. Results demonstrated a significant difference in GM muscle strength in female athletes with LBP compared to athletes without LBP $(\mathrm{p}=0.04)$. The results support the proposal that GM muscle imbalance can contribute to the transmission of abnormal forces up the kinetic chain to the spine, increasing the risk for the development of LBP.

\section{CLINICAL RELEVANCE AND IMPLICATIONS}

\section{Injury prevention}

It remains a challenge for physiotherapists to use effective pre-season musculoskeletal assessment to identify any existing muscle imbalance, so that rehabilitation can attempt to prevent injuries. Research into this area will provide a much-needed emphasis shift from injury treatment to injury prevention. If corrected, the athlete can return to the sport unrestricted, rather than ending up with a chronic condition due to a muscle imbalance (Schlink 1990). Grace (1985) states that if a muscle imbalance is recognized and corrected, it could hypothetically decrease the incidence of athletic injury.

\section{Assessment of muscle imbalance}

It is imperative that physiotherapists, working with athletes, know whether a muscle imbalance is a specific adaptation to that sport. Previously, decreased muscle activity was considered to be muscle weakness, without questioning the cause. The resulting weakness could be due to altered movement patterns, i.e. due to changed motor regulation and motor performance (Janda 1986; Richardson et al. 1999). Janda (1986) suggests that movement patterns must be assessed for a changed muscle firing order due to delayed muscle activation (the non-inhibited synergists usually become activated earlier) and/or decreased activity of a specific muscle. This is in agreement with what Richardson et al. (1999, 2000) is implementing during assessment of the trunk musculature. The focus is therefore on the muscle firing order and/or muscle activity during movements using EMG.

This proposal supports a focus change from the actual muscle weakness to the movement pattern (muscle activity and muscle firing order). Although muscle testing identifies any deficit as a result of weakness and length changes, it does not give information about poor motor control, and therefore manual muscle testing of the synergists, as well as observation of movement patterns have to be used to support the hypothesis of altered recruitment patterns (Sahrmann 2002). Weakness of the one synergist should be consistent with inadequate participation of this non-dominant synergist. The dominant synergist is then susceptible to an overuse injury (Sahrmann 2002). Schlink (1990) states that poor quality of movement and substitution or compensatory patterns will portray the presence of muscle imbalance and direct treatment better. The above implies that in hockey players one should test the muscle strength of the GM and hamstring muscle using for example manual muscle testing (according to Kendall 1993), kinetic control testing (Comerford, Mottrom \& Gibbons 2005) or isokinetic testing (if the facilities are available). In addition the movement pattern of hip extension in prone should be assessed. Weak GM will be confirmed with increased activity of the hamstring and ES, as well as possibly an increase in the lumbar lordosis. This can be done visually or using EMG if available. EMG and isokinetic testing is not readily available to most clinicians. Though, the innovative kinetic control testing described by Comerford, Mottrom \& Gibbons 2005 allows for testing muscle strength and movement patterns efficiently and objectively in everyday clinical practice.

\section{The need for more data}

Studies by Nadler et al. (2000, 2001) supported the screening of hip extensor strength, as it may be significant in the prevention of LBP in female athletes. The role of the hip extensors has not been specifically assessed in female field hockey players. Mayer (1987) has identified the lack of a sport-specific database for athletes training in a physically demanding sport. There is a need to establish a baseline reference as prerequisite for future clinical studies of female field hockey players with LBP or 
other injuries. The baseline data can be added to the research that has been completed on female field hockey players, including isokinetic trunk strength and endurance, as well as sagittal and horizontal lumbar ROM (Fenety \& Kumar 1992; Lindgren \& Twomey 1988). In addition, it must be realised that assessment of apparently healthy athletes can reveal specific deficiencies in flexibility or muscle strength, which may predispose the athlete to injury (Agre \& Baxter 1987) and can assist during the rehabilitation of the injured athlete (Alexander 1990). It is thus imperative that baseline data is obtained specific, relevant and functional to that sport.

\section{SUMMARY}

Despite the high incidence of LBP among field hockey players, only a few of the risk factors predisposing LBP have been assessed in this population. The posture a player adapts playing hockey causes unique stresses on the musculoskeletal system, especially the hip extensor muscles. This can lead to changes in the muscle and movement pattern, thus causing injury. The link between LBP and GM weakness is well documented throughout the literature (Janda 1986; Kankaanpää et al. 1998; Leinonen et al. 2000; Nadler et al. 2000, 2001). This however, has not been considered as a risk factor for the development of LBP among field hockey players. Baseline data on the hip extensor muscles of female field hockey players can be used for further clinical studies on female field hockey players with LBP or lower extremity injuries. This will assist in identifying risk factors for the development of LBP, aiding the physiotherapy profession to function preventatively, and not only curatively. The detection of muscle imbalance as a risk factor is very important and needs to be assessed specific to the sport.

Considering that GM imbalance may be a predisposing factor to the development of LBP due to the transmission of abnormal forces to the spine (Nadler et al. 2001), and that the hip muscles play a significant role in transferring forces from the lower extremity up to the spine (Porterfield \& DeRosa 1998), the hip extensors of field hockey players warrants further investigation towards prevention of LBP in this population group.

\section{REFERENCES}

Alexander MJL 1990 Peak torque values for antagonist muscle groups and concentric and eccentric contraction types for elite sprinters. Archives of Physical Medicine and Rehabilitation 71: 334-339

Agre JS, Baxter TL 1987 Musculoskeletal profile of male collegiate soccer players. Archives of Physical Medicine and Rehabilitation 68: 147-150

Beckman SM, Buchanan TS 1995 Ankle inversion injury and hypermobility: effect on hip and ankle muscle electromyography onset latency. Archives of Physical Medicine and Rehabilitation 76: 1138-1143

Biering-Sorenson F 1984 Physical measurements as risk indicators for low-back trouble over a one-year period. Spine 9: 106-119

Bullock-Saxton JE 1994 Local sensation changes and altered hip muscle function following severe ankle sprain. Physical Therapy 74: 17-31

Comerford MJ, Mottrom SL Gibbons SGT 2005 Kinetic control: Diagnosis of Mechanical Back Pain sub groups and stability retraining of the lumbar spine Course notes 2005

Fairbank JCT, Pynset PB, Van Portliet JA, Phillips H 1984 Influence of anthropometric factors and joint laxity in the incidence of adolescent back pain. Spine 9: 461-464

Fenety A, Kumar S 1992 Isokinetic trunk strength and lumbosacral range of motion in elite female field hockey players reporting low back pain. Journal of Orthopaedic and Sports Physical Therapy 16: 129-135

Fox N 1981 Risks in Field Hockey. In: Reilly R (ed) Sports Fitness and Sports Injuries, pp112117. Faber \& Faber, Boston

Fuller MI 1990 A study of injuries in Women's field hockey as played on synthetic turf pitches. Physiotherapy in Sport (London) 12: 3-6

Giles LGF, Taylor JR 1981 Low-back pain associates with leg length inequality. Spine 6: 510-521

Grace TG 1985 Muscle imbalance and extremity injury. A perplexing relationship. Sports Medicine 2: 77-82

Hodges PW, Richardson CA 1996 Inefficient muscular stabilization of the lumbar spine associated with low back pain. Spine 21: 2640-2650
Indahl A, Kaigle A, Reikeras O, Holm S 1999 Sacroiliac joint involvement in activation of the porcine spinal and gluteal musculature. Journal of Spinal Disorders 12: 325-330

Janda V 1978 Muscles, central nervous motor regulation and back problems. In: Korr (ed) The neurobiologic mechanisms in manipulative therapy pp 29. Plenum Press, London

Janda V 1986 Muscle weakness and inhibition (pseudoparesis) in back pain syndromes. In: Grieve GP (ed) Modern manual therapy of the vertebral column pp 197-201. Churchill Livingstone, Edinburgh

Kankaanpää M, Taimela S, Laaksonen D, Hänninen O, Airaksinen O 1998 Back and hip extensor fatigability in chronic low back pain patients and controls. Archives of Physical Medicine and Rehabilitation 79: 412-417

Karlsson E, Jonsson B 1965 Function of the gluteus maximus muscle. Acta Morphologica Neerlando-Scandinavica 6: 161-169

Kendall FP, McCreary EK, Provance PG. Muscles Testing and Function. 4th ed. Baltimore: Williams \& Wilkins 1993; 226-227.

Knapik JJ, Bauman CL, Jones BH, Harris J, Vaughan L 1991 Preseason strength and flexibility imbalances associated with athletic injuries in female collegiate athletes. The Journal of Sports Medicine 19: 76-81

Leinonen V, Kankaanpää M, Airaksinen O, Hänninen O 2000 Back and hip extensor activities during trunk flexion/extension: Effects of low back pain and rehabilitation. Archives of Physical Medicine and Rehabilitation 81: 32-37

Levangie PK, Norkin CC 2001 Joint Structure and Function - A Comprehensive Analysis, 3rd edn. pp 95-96, 307-312. FA Davis Company, Philadelphia

Lindgren S, Twomey L 1988 Spinal mobility and trunk muscle strength in elite hockey players. The Australian Journal of Physiotherapy 34: 123-129

Marzke MW, Longhill JM, Rasmussne SA 1988 Gluteus maximus muscle function and the origin of hominid bipedality. American Journal of Physical Anthropology 77: 519-528

Mayer TG 1987 Assessment of lumbar function. Clinical Orthopaedics and Related Research 221: 99-109

Mayer TG, Tencer TF, Kristofereon S, Mooney V 1984 Use of non-invasive techniques for quantification of spinal range-of-motion in normal subjects and chronic low-back dysfunction patients. Spine 9: 588-595 
McGill SM, Childs A, Liebenson C 1999 Endurance times for low back stabilization exercises: clinical targets for testing and training from a normal database. Archives of Physical Medicine and Rehabilitation 80: 941-944

McNeill T, Warwich D, Andersson G, Schults A 1980 Trunk strengths in attempted flexion, extension and lateral bending in healthy subjects and patients with low-back disorders. Spine 5: 529-537

Murtaugh K 2001 Injury patterns among female field hockey players. Medicine and Science in Sports and Exercise 33: 201-207

Nadler SF, Wu KD, Glaski T, Feinberg JH 1998 Low back pain in college athletes: A prospective study correlating lower extremity overuse or acquired ligamentous laxity with low back pain. Spine 23: 828-833

Nadler SF, Malanga GA, DePrince ML, Stitik TP, Feinberg JH 2000 The relationship between lower extremity injury, low back pain, and hip muscle strength in male and female collegiate athletes. Clinical Journal of Sports Medicine 10: 89-97

Nadler SF, Malanga GA, Feinberg JH, Prybicien M, Stitik TP, DePrince M 2001 Relationship between hip muscle imbalance and occurrence of low back pain in collegiate athletes. American Journal of Physical Medicine and Rehabilitation 80: 572-577

Petrick M, Laubscher KF, Peters EM 1992 Hockey injuries in High School first team schoolgirl players of Southern Transvaal and Qriqualand West. Sportgeneeskunde 7: 9-16
Pierce MN, Lee WA 1990 Muscle firing order during active prone hip extension. The Journal of Orthopaedic and Sports Physical Therapy 12: 2-9

Porterfield JS, DeRosa S 1998 Mechanical low back pain. Perspectives in functional anatomy 2nd edn. pp101-108. WB Saunders Company, Philadelphia

Reilly T, Seaton A 1990 Physiological strain unique to field hockey. The Journal of Sports Medicine and Physical Fitness 30: 142-146

Richardson CA, Jull GA, Hides JA 2000 A new clinical model of the muscle dysfunction linked to the disturbance of spinal stability: Implications for treatment of low back pain. In: Twomey TL, Taylor JR (ed) Physical Therapy of the Low Back. 3rd edn. pp 249267. Churchill Livingstone, London

Richardson C, Jull G, Hodges P, Hides J 1999 Therapeutic Exercise for Spinal Segmental Stabilization in Low Back Pain. Scientific Basis and Clinical Approach pp 63-68. Churchill Livingstone, London

Sahrmann SA 2002 Diagnosis and Treatment of Movement Impairment Syndromes pp1516, 35-37. Mosby Inc

Schlink MB 1990 Muscle imbalance patterns associated with low back syndromes. In: Hochschuler SH (ed) The spine in sports ch 11 pp 146-156. Harley \& Belfus, Philadelphia

Schwarzer A, April CN, Bogduk N 1995 The sacroiliac joint in chronic low back pain. Spine 20: 31-37
Singer KP 1986 A new musculoskeletal assessment in a student population. The Journal of Orthopaedic and Sports Physical Therapy 8: 34-41

Souza GM, Baker LL, Powers CM 2001 Electromyographic activity of selected trunk muscles during dynamic spine stabilization exercises. Archives of Physical Medicine and Rehabilitation 82: 1551-1557

Stevenson MR, Hmaer P, Finch CF, Elliot B, Kresnow M 2000 Sport, age, and sex specific incidence of sports injuries in Western Australia. British Journal of Sports Medicine 34: 188-194

Vleeming A, Pool-Goudzwaard AL, Stoeckart R, van Wingerden J, Snijders CJ 1995 The posterior layer of the thoracolumbar fascia. Spine 20: 753-758

Vogt L, Banzer 1997 Dynamic testing of the motor stereotype in prone hip extension from neutral position. Clinical Biomechanics 12: 122-127

Vogt L, Pfeifer K, Banzer W 2003 Neuromuscular control of walking with chronic low-back pain. Manual Therapy 8: 21-28

Watson AWS 1997 Injuries in schoolboy players of basketball, field hockey, hurling, Gaelic football, rugby and soccer. New Zealand Journal of Sports Medicine 25: 22-24 